\title{
Preparation of Environmentally Friendly and Energy-saving Autoclaved Aerated Con- crete using Gold Tailings
}

\author{
Feihua Yang ${ }^{1}$, Xiaoying Liang ${ }^{2, *}$, Yi Zhu ${ }^{3}$, Changlong Wang ${ }^{2,45, *}$, Gaofei $\mathrm{Zhao}^{2}$, Xiaowei Cui ${ }^{6}$ \\ ${ }^{1}$ State Key Laboratory of Solid Waste Reuse for Building Materials, Beijing Building Materials Academy of Science Research, Bei- \\ jing 100041,China; \\ ${ }^{2}$ School of Civil Engineering, Hebei University of Engineering, Handan Hebei Province, 056038, China; \\ ${ }^{3}$ China National Institute of Standardization, Beijing 100191, China; \\ ${ }^{4}$ Jiangxi Key Laboratory of Mining Engineering, Jiangxi University of Science and Technology, Ganzhou Jiangxi Province 341000, \\ China; \\ ${ }^{5}$ Tianjin Sunenergy Sega Environmental Science \& Technology Co. Ltd, Tianjin 300000, China; 6. Shaanxi Key Laboratory of \\ Comprehensive Utilization of Tailings Resources, Shangluo University, Shangluo Shaanxi Province 726000, China
}

Corresponding Author Email: 844065183@qq.com; baistuwong@139.com

\begin{abstract}
In order to realize the resource utilization of gold tailings (GTS), autoclaved aerated concrete (ACC) was prepared as the main siliceous material. The optimum proportions of calcium materials in GTS AAC were obtained by adjusting the content of calcium materials, and the effect mechanism of calcium materials on AAC was studied. The results showed that when the specific surface area (SSA) of GTS is $367 \mathrm{~m}^{2} \cdot \mathrm{kg}^{-1}$ and he is 62 (in mass, the same below), the ACC was prepared with bulk density of $584 \mathrm{~kg} \mathrm{~m}^{-3}$ and compressive strength of $5.85 \mathrm{MPa}$, which passed the requirements of A3.5, B06 level of AAC sample regulated by GB/T 11969-2008. X-ray diffraction analysis (XRD) and scanning electron microscope (SEM) analysis show that the main hydration products are tobermorite, aluminum tobermorite, and CSH(B). The hydration products are interspersed with each other to form a cohesive structure, which effectively improve the strength of the products.
\end{abstract}

Keywords: gold tailings, autoclaved aerated concrete, calcium materials, tobermorite

Received: May-03-2019, Accepted: July-07-2019, https://doi.org/10.14447/jnmes.v22i3.a08

\section{INTRODUCTION}

Gold tailings (GTS) are solid wastes from gold mining operations by mining enterprises. At present, China's GTS are basically in a state of tailings storage. According to statistics, from 2014 to 2018, the national GTS emissions reached 920 million tons, which brought serious environmental and safety problems to the mining area. Therefore, it has become a top priority to conduct secondary development and utilization of resources for the GTS [1]. Due to its high silicon content, the GTS can be used as the admixtures to prepare autoclaved aerated concrete (AAC). This can effectively absorb a large amount of GTS, which makes it one of the key projects of the 12th Five-Year Plan for comprehensive utilization of bulk industrial solid wastes [2].

AAC is a porous building material, and one of its most outstanding advantages is light weight, while the porosity is the cause of its light weigh $[3,4]$. Some literatures show that the reason why the AAC's strength can be ensured under light weight is that during the autoclaving process, the hardened aerated concrete produced a large amount of well-crystalline tobermorite and crystalline phase calcium silicate hydrate $(\mathrm{CSH})$, which cross-grow with gel-like substances to compact the structure and thus improve product strength and performance [512]. After crushing, grinding and beneficiation, the fine-grained GTS are rich in silicate minerals. They differ greatly in the physical and chemical characteristics from acid materials such as fly ash and river sand that are commonly used in the production of aerated concrete $[13,14]$. The active ingredients of silicate minerals, such as $\mathrm{Al}_{2} \mathrm{O}_{3}$ and
$\mathrm{SiO}_{2}$, are susceptible to hydration reactions in high-temperature and high-pressure alkaline hydrothermal environments, producing hydration products such as the CSH gels, etc. The use of silicate-rich mineral tailings produced by metal mines to produce aerated concrete has already been successfully applied in China. In view of the above, this study uses the GTS as the siliceous material, cement and lime as the calcium materials to prepare the AAC.

The batching is an important procedure in the AAC production process. The purpose of batching pouring is to make the pores in the slurry meet the requirements and form a good green body. For the AAC, under the condition of certain siliceous materials, the choice and content of calcium materials have different effects on its performance. Generally, calcium materials mainly include cement and lime. When using cement alone, not only a large quantity is needed, but the green body is hardened slowly at a low strength; the use of lime alone is not convenient for quality control. Compared with the single calcium material, the use of a mixed calcium material can ensure a better casting performance of the slurry and higher strength of the product at an appropriate mixing ratio. Therefore, in this study, the tests were conducted to study the content of calcium materials (cement, lime) in the AAC doped with the GTS, and testing methods of X-Ray diffraction (XRD), scanning electron microscope (SEM) were used to analyse the hydration mechanism of such AAC. 


\section{MATERIALS AND METHODS}

\subsection{Raw materials}

The AAC samples were prepared using the following raw materials: GTS, lime, 42.5 ordinary Portland cement (OPC) and the gypsum of flue gas desulfurization gypsum (FGDG). The chemical compositions of the raw materials are listed in Table 1.

(1) GTS. The siliceous material of the secondary tailings after remineralization by extracting the residual gold-bearing sulphides and magnetite. The original ore type of the GTS is altered rock, and the genetic type is hydrothermal immersion type. Although a certain fineness has been reached during the beneficiation process $(13 \%$ of the $0.08 \mathrm{~mm}$ square-hole sieve), the fineness of the tailings discharged from the beneficiation plant still fails to meet the requirements for producing the aerated concrete, and further grinding is required before use. The main mineral constituents are quartz, sericite, microcline, albite and cancrinite (Fig. 1).

(2) OPC. 42.5 ordinary Portland cement, with a specific surface area of $355 \mathrm{~m}^{2} \cdot \mathrm{kg}^{-1}$, an initial setting time of 125 minutes, a final setting time of 220 minutes, and a water consumption of normal consistency of $24.2 \%$.

(3) Lime. The digestion time of lime $15 \mathrm{~min}$, the digestion temperature $65^{\circ} \mathrm{C}$, the effective $\mathrm{CaO}$ content $>60 \%$, and the sieve residue of $0.08 \mathrm{~mm}$ sieve $12 \%$ to $15 \%$.

(4) FGDG. The flue gas desulfurization gypsum produced by desulfurization process in thermal power plant, with the specific surface area (SSA) of FGDG for $216 \mathrm{~m}^{2} \cdot \mathrm{kg}^{-1}$, and the $0.08 \mathrm{~mm}$ sieve residue of $8 \%$.

(5) Other materials. Using the aluminium powder as foaming agent; preparing the foam stabilizer from oleic acid, triethanolamine and water at a certain ratio under room temperature.

\subsection{Test method}

\subsubsection{AAC Preparation}

The total amount of calcium materials and the relative content of cement and lime have a significant effect on product performance. Based on this, the test was mainly designed to study the effect and then determine the $\mathrm{Ca} / \mathrm{Si}$ ratio.

The GTS was first dried to a moisture content of less than $1 \%$, and then placed in a $5 \mathrm{~kg}$ laboratory ball mill $(\mathrm{SM} \varphi 500 \mathrm{~mm} \times 500 \mathrm{~mm})$ for

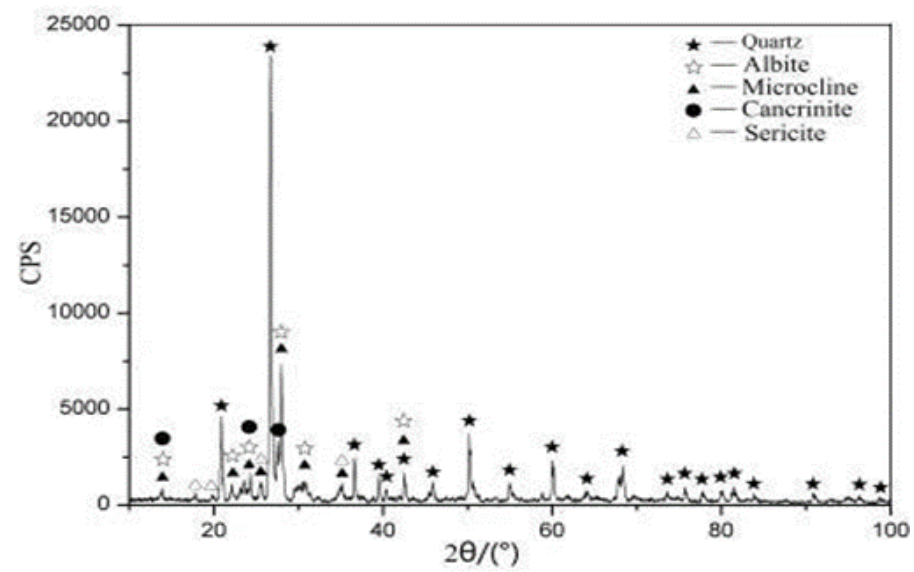

Figure 1. XRD spectrum of GTS grinding. The rotation speed of the mill was $48 \mathrm{r} \cdot \mathrm{min}^{-1}$, the grinding medium was steel balls and steel forgings, and the loading capacity of the grinding medium was $100 \mathrm{~kg}$. Among them, the steel balls were 60 $\mathrm{kg}$; the quality gradation was $\Phi 70 \mathrm{~mm}$ accounting for $19.7 \%, \Phi 60 \mathrm{~mm}$ $33.1 \%$, $Ф 50 \mathrm{~mm} 29.6 \%$, and $\Phi 40 \mathrm{~mm} \mathrm{17.6 \%}$; steel forgings were 40 $\mathrm{kg}, \Phi 25 \mathrm{~mm} \times 30 \mathrm{~mm}$ in size. The grinding time and the corresponding SSA are shown in Fig. 2.

According to the requirements of GB/T 12957-2005 Test Method for Activity of Industrial Waste Slag Used as Addition to Cement and GB/T 17671-1999 Method of Testing Cements-Determination of Strength, the tests were conducted on the ground GTS. Combining the test results with the actual energy consumption during the mechanical activation of the GTS, the activation time is set to $30 \mathrm{~min}$, and the corresponding specific surface area is $367 \mathrm{~m}^{2} \cdot \mathrm{kg}^{-1}$.

Based on the optimal mixture ratio obtained in the preliminary laboratory test, firstly mix the GTS, cement, lime and gypsum at a mass ratio of $60: 25: 10: 5$, and add hot water $\left(\right.$ at $55{ }^{\circ} \mathrm{C}$ ) for about $61 \%$ of the total mass of dry materials; then add $0.06 \%$ aluminium powder and $0.0256 \%$ from the dry materials, and stir for $40 \mathrm{~s}$; next, pour it into a mould of $100 \mathrm{~mm} \times 100 \mathrm{~mm} \times 100 \mathrm{~mm}$; finally, autoclaved aerated concrete samples were finished after the static curing, demoulding, and autoclaving. The ambient temperature for gas generation and static curing was $55^{\circ} \mathrm{C}$, lasting for 3 hours; the autoclave curing conditions included 1.25 $\mathrm{MPa}$ steam pressure, $185^{\circ} \mathrm{C}$ temperature, and 8 hours autoclave constant holding time. The powder samples after grinding were taken for X-ray diffraction (XRD) test; samples were used for the scanning electron microscope (SEM) test, and they must have a complete pore structure (the test surface is a natural cross-section, without wear).

\subsubsection{Test methods}

A Rigaku D/Max-RC powder crystal X-ray diffractometer from Japan was used for XRD analysis, with the $\mathrm{Cu}$ target, a working voltage of $40 \mathrm{kV}$, a current of $100 \mathrm{~mA}$, a scanning speed of $4 \%$ min, a scanning range of $10^{\circ}$ to $90^{\circ}$, and step length of 0.02 ; S250 SEM was adopted, with the working voltage of $20 \mathrm{kV}$. The test process was mainly performed in secondary electron (SE1) mode.

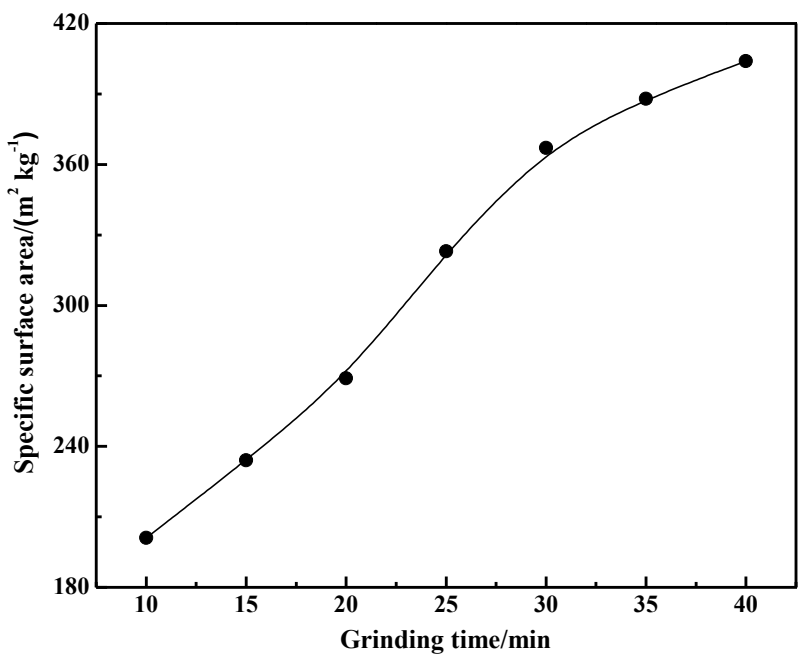

Figure 2. Relationship between grinding time and SSA of GTS

Table 1. Chemical composition of raw materials (mass fraction, \%)

\begin{tabular}{lccccccccccc}
\hline Materials & $\mathrm{SiO}_{2}$ & $\mathrm{Al}_{2} \mathrm{O}_{3}$ & $\mathrm{Fe}_{2} \mathrm{O}_{3}$ & $\mathrm{FeO}$ & $\mathrm{MgO}$ & $\mathrm{CaO}$ & $\mathrm{K}_{2} \mathrm{O}$ & $\mathrm{Na}_{2} \mathrm{O}$ & $\mathrm{SO}_{3}$ & $\mathrm{LOI}$ \\
\hline GTS & 73.83 & 12.16 & 0.77 & 0.60 & 2.08 & 1.68 & 4.24 & 2.89 & 0.21 & 1.69 \\
OPC & 22.19 & 4.15 & 3.19 & 0.36 & 1.35 & 63.87 & 0.71 & 0.54 & - & 2.97 \\
Lime & 10.98 & 3.85 & 0.90 & 0.08 & 3.59 & 68.76 & 1.25 & 0.39 & 0.45 & 6.83 & -25 \\
FGDG & 2.85 & 0.79 & 0.26 & 0.02 & 0.48 & 40.23 & 0.13 & 0.08 & 33.22 & - \\
\hline
\end{tabular}




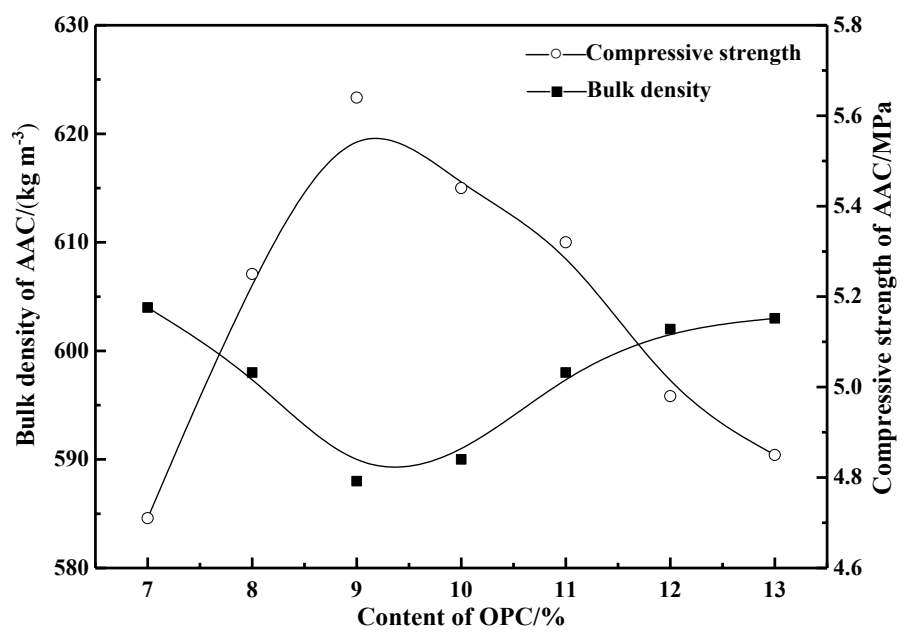

Figure 3. Effect of OPC content on AAC samples properties

\section{RESULTS AND DISCUSSION}

\subsection{Effect of OPC content on AAC properties}

Cement is one of the important calcium materials to produce the AAC. It can be used as a calcium material in the AAC alone or as a mixed calcium material with lime. Its role in aerated concrete is mainly to provide $\mathrm{CaO}$, which can react with free $\mathrm{SiO}_{2}$ and $\mathrm{Al}_{2} \mathrm{O}_{3}$ in iron tailings under autoclaving conditions to produce minerals such as the $\mathrm{CSH}$ and hydrated calcium aluminosilicate. With the fixed ratios of other materials, the author explored the relationship between different cement content and the AAC strength doped with the GTS in Fig. 3.

It can be seen from Fig. 3 that when the OPC content increased from $7 \%$ to $13 \%$, the strength of the product increased, but when it continued to increase, the compressive strength decreased instead; under this condition, the compressive strength decreased first and then increased. The main reason for this is that the excessive content of cement and too many calcium materials can easily lead to $\mathrm{CaO}$ residue, and form a dual-alkali hydrate in the entire system, which eventually results in a reduction of the strength of the AAC sample, for the strength of the dual-alkali hydrate is higher than that of the single alkali hydrate. Therefore, the optimal cement content is selected to be $9 \%$.

\subsection{Effect of lime content on AAC properties}

Lime is a calcium material for the AAC production. Its main role is to provide effective calcium oxide through the AAC matching, so that it can interact with $\mathrm{SiO}_{2}$ and $\mathrm{Al}_{2} \mathrm{O}_{3}$ in siliceous materials under hydrothermal conditions to generate the $\mathrm{CSH}$ and hydrated calcium aluminosilicate, thereby enhancing the product strength. Also, lime can increase the alkalinity of the AAC slurry, provide the conditions for the aeration of the aluminium powder, and then promote its aeration reaction. Fig. 4 shows the influence curves of different lime content on the AAC strength when the ratio of GTS, OPC and FGDG was 60:10:5.

It can be seen from Fig. 4 that as the lime content increased, the compressive strength of the AAC increased, and the bulk density decreased; when the lime content was $24 \%$, the compressive strength and bulk density reached the optimal. After that, as the amount of lime increased continuously, the compressive strength began to decrease, and the bulk density turned to increase. This indicates that when the content of lime is too much, the lime shall release a lot of heat during the digestion process, increase the temperature of the slurry, and accelerate the thickening speed, which may cause obstacles to the gas generation of aluminium powder and the smooth expansion of the slurry, and even cracks on the surface of the slurry, unfavourably affecting the product strength. Conversely, with too little lime added, the limited heat re-

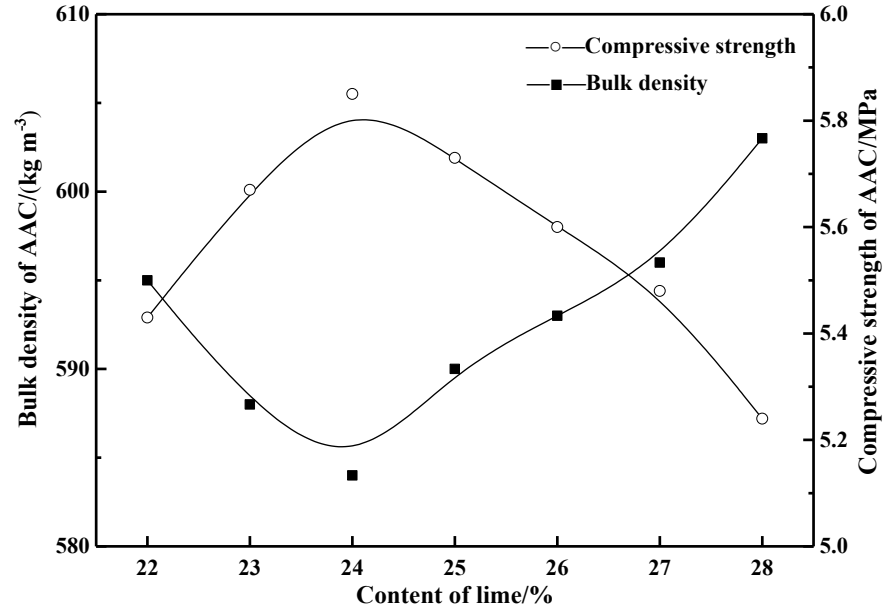

Figure 4. Effect of lime content on AAC samples properties

leased during the lime digestion process, and the slow thickening of slurry thickens can easily lead to large bubbles and the overflowing of the slurry out of the mould, and in severe cases, cause the mould to collapse, which also affects the strength of the product. Based on the above analysis, the optimal lime content is determined to be $24 \%$.

\subsection{Analysis for the role of calcium materials}

The effect of the calcium materials (cement and lime content) on the performance of the product is mainly reflected in the pouring stability. With too much cement used, the green body hardens slowly, shrinks and sinks easily; with too much lime, the slurry thickens quickly, and the green body is prone to cracks, resulting in the insufficiency in the later strength.

In this study, the mixed calcium materials were used for the AAC. The formation of this ideal structure makes its contribution to higher strength and lower bulk density of the AAC in two aspects: one is to form a good pore structure during the pouring process, which requires the consistency between the aeration speed of aluminium powder and the slurry thickening speed; the second is that a good crystal structure is formed during the autoclaving process.

The low-alkali CSH has many covalent bonds and few ionic bonds with small crystal size and large specific surface area. The crystalline continuum produced by such crystals has many contact points, and the particles are firmly connected with each other and have strong binding force, ensuring the high strength of the product; on the contrary, the high-alkali CSH leads to a low strength of the product. Therefore, in the mineral composition of the product, it's better to have more lowalkali hydrate minerals, and form a multi-mineral gelling substance composed of two or more CSHs and other hydrated minerals, thereby achieving a more compact microcrystalline structure.

The lime in the slurry reacted with the GTS and cement under high temperature and high pressure to form various CSH. Because the siliceous material used was more than the calcium materials, a large dispersity of the calcium material might enable the lime in the slurry to be completely combined into $\mathrm{C}_{2} \mathrm{SH}(\mathrm{A})\left(\mathrm{C}_{2} \mathrm{SH}_{2}\right)$; as the autoclaving process continued, the $\mathrm{SiO}_{2}$ concentration in the liquid phase increased, and the $\mathrm{C}_{2} \mathrm{SH}(\mathrm{A})$ that was formed cannot exist stably so that the existing crystals and their continuum began to decompose and destroy, and form low-alkali CSH under the new conditions, such as CSH (B) and tobermorite.

Based on the above analysis, the effect of the total amount of calcium materials on the product performance is as follows: if the total amount of calcium materials is too small, it cannot generate sufficient hydrates and ensure the sufficient depth of the hydration layer; if it's 


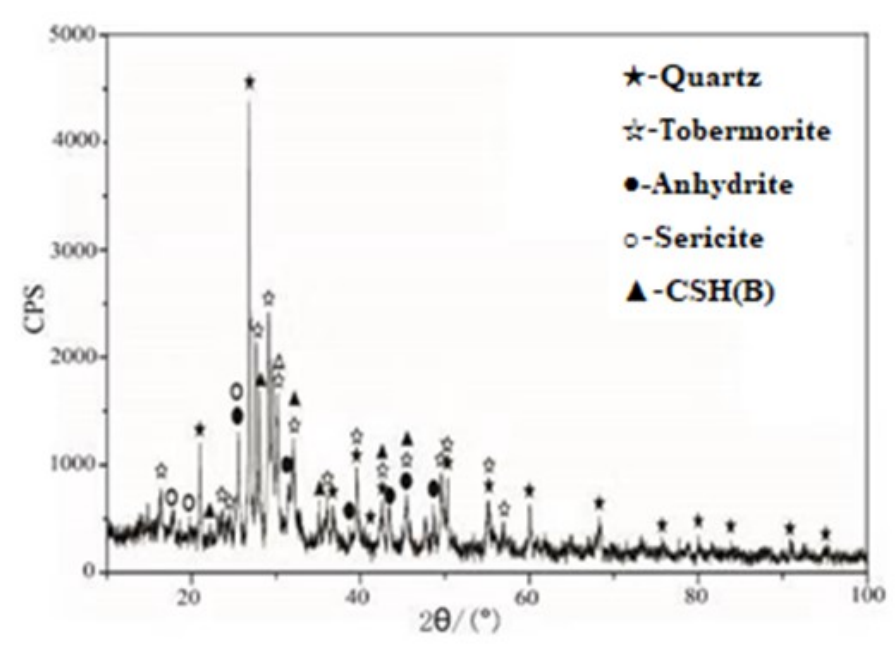

Figure 5. XRD spectrum of AAC samples
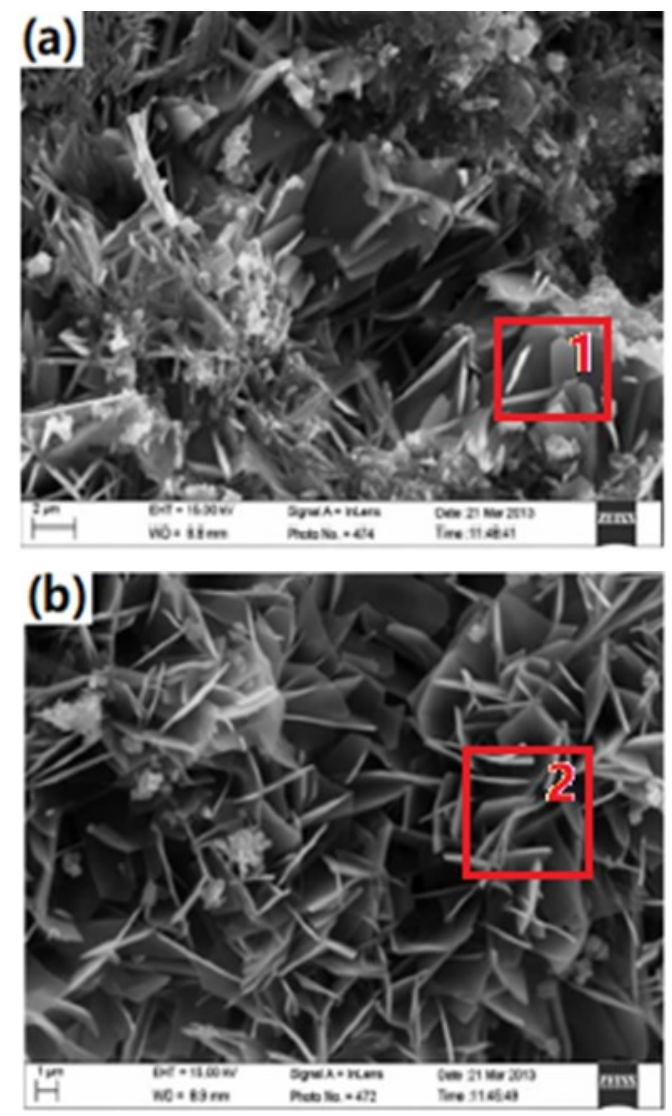

Figure 6. SEM micrographs of AAC samples. (a) internal section of hole wall, (b) Outer surface of hole wall

too large, it shall fail to form low-alkali CSH smoothly, and has the hydrate with insufficient crystallinity. The ideal practice is to intertwine an appropriate number of coarse crystal continuum with various fine crystal hydrates, such as the well-crystallized tobermorite in the weakly crystallized $\mathrm{CSH}(\mathrm{B})$, which can significantly improve the product strength. The analysis of the hydration reaction product shows that the test products are more in line with the ideal structure described above, and therefore has higher strength.

Due to limited conditions, the tests did not consider the effect of different autoclaving systems on product performance. It can be imagined that in actual production, due to the large total volume of the body, the constant temperature time needs to be more than 8 hours when considering the time difference between the inside and outside of the green body. Whereas, the test mould was small, generally 5-hour constant temperature can meet the requirements. If it's too long under the constant temperature time, most $\mathrm{CSH}(\mathrm{B})$ may be transformed into tobermorite with large crystals, which destroys the ideal structure of crystal cross-growth, and reduce the strength. This needs to be verified specifically through experiments.

\subsection{Analysis of hydration products}

\subsubsection{Phase analysis of hydration products}

XRD was used to analyse the composition of the AAC sample, e.g., qualitatively analyse various hydrated minerals dominated by calcium silicate to determine the type of hydration products, and semiqualitatively analyse their amount of formation, which has a decisive influence on the performance of the AAC. Fig. 5 shows the XRD spectrum of the AAC sample under the optimal blending of various factors.

It can be seen from Fig. 5 that the main phases of the AAC products after high temperature and high-pressure curing were the hydration products such as tobermorite and CSH (B), as well as the anhydrite, quartz, and sericite.

In the initial stage of autoclaving, the dissolution rate of lime in the raw materials system was different from that of quartz with crystalline characteristics. Quartz was dissolved in the liquid phase and combined with the $\mathrm{Ca}(\mathrm{OH})_{2}$ to generate different types of CSHs. Such hydrate is hardly soluble in water and easily forms a saturated solution. Therefore, compared with lime, quartz is easier to dissolve out. CSH was the first to be formed on the surface of the sand grains; the single alkali CSH was formed near the sand grains, $\mathrm{C}_{2} \mathrm{SH}(\mathrm{A})$ was formed far away from the sand grains, and free $\mathrm{CaO}$ that has no time to bind existed farther. As the autoclaving curing temperature increased, the $\mathrm{SiO}_{2}$ activity in iron tailings increased, and more $\mathrm{SiO}_{2}$ reacted with $\mathrm{Ca}(\mathrm{OH})_{2}$ to form $\mathrm{CSH}$ gels. When more and more $\mathrm{SiO}_{2}$ was dissolved, the $\mathrm{C} / \mathrm{S}$ in the liquid phase would decrease, and the bi-alkali CSH gels formed in the early stage of cement hydration would react with $\mathrm{SiO}_{2}$ to form a lowalkali CSH gels and tobermorite. The autoclaving process is essentially the reaction of active $\mathrm{SiO}_{2}$ and $\mathrm{Al}_{2} \mathrm{O}_{3}$ components with lime and cement gels under superheated steam pressure. The strength of the AAC was obtained by the hydration products $\mathrm{CSH}$ (B) and tobermorite which were produced by the reaction of the active ingredients with $\mathrm{Ca}(\mathrm{OH})_{2}$. The reaction of active $\mathrm{SiO}_{2}$ and $\mathrm{Al}_{2} \mathrm{O}_{3}$ with $\mathrm{Ca}(\mathrm{OH})_{2}$ are shown in formula (1) and (2).

$$
\begin{aligned}
& \mathrm{xCa}(\mathrm{OH})_{2}+\mathrm{SiO}_{2}+\mathrm{mH}_{2} \mathrm{O} \rightarrow \mathrm{xCaO} \cdot \mathrm{SiO}_{2} \cdot \mathrm{mH}_{2} \mathrm{O} \\
& \mathrm{yCa}(\mathrm{OH})_{2}+\mathrm{Al}_{2} \mathrm{O}_{3}+\mathrm{nH}_{2} \mathrm{O} \rightarrow \mathrm{yCaO} \cdot \mathrm{Al}_{2} \mathrm{O}_{3} \cdot \mathrm{nH}_{2} \mathrm{O}
\end{aligned}
$$

Under autoclave curing conditions, the $\mathrm{Si}-\mathrm{O}$ bond and $\mathrm{Al}-\mathrm{O}$ bond in the $\mathrm{SiO}_{4}$ tetrahedron of GTS were broken in an alkaline environment, which is conducive to the dissolution of more $\mathrm{SiO}_{2}$ and $\mathrm{Al}_{2} \mathrm{O}_{3}$, and combination with $\mathrm{Ca}(\mathrm{OH})_{2}$ to produce more $\mathrm{CSH}$ gels and tobermorite etc.

Anhydrite was formed in the XRD pattern of the finished sample, as the residue after the reaction of FGDW in the system. Compared with Fig. 1, the diffraction peaks of quartz and sericite were significantly reduced, indicating that they both partly participated in the hydrothermal reaction of the system, while microcline, albite, and cancrinite were decomposed completer after the reaction. The remaining minerals quartz, sericite and anhydrite acted as aggregates in the product to support it, so that the AAC product obtained a sufficiently high strength. 

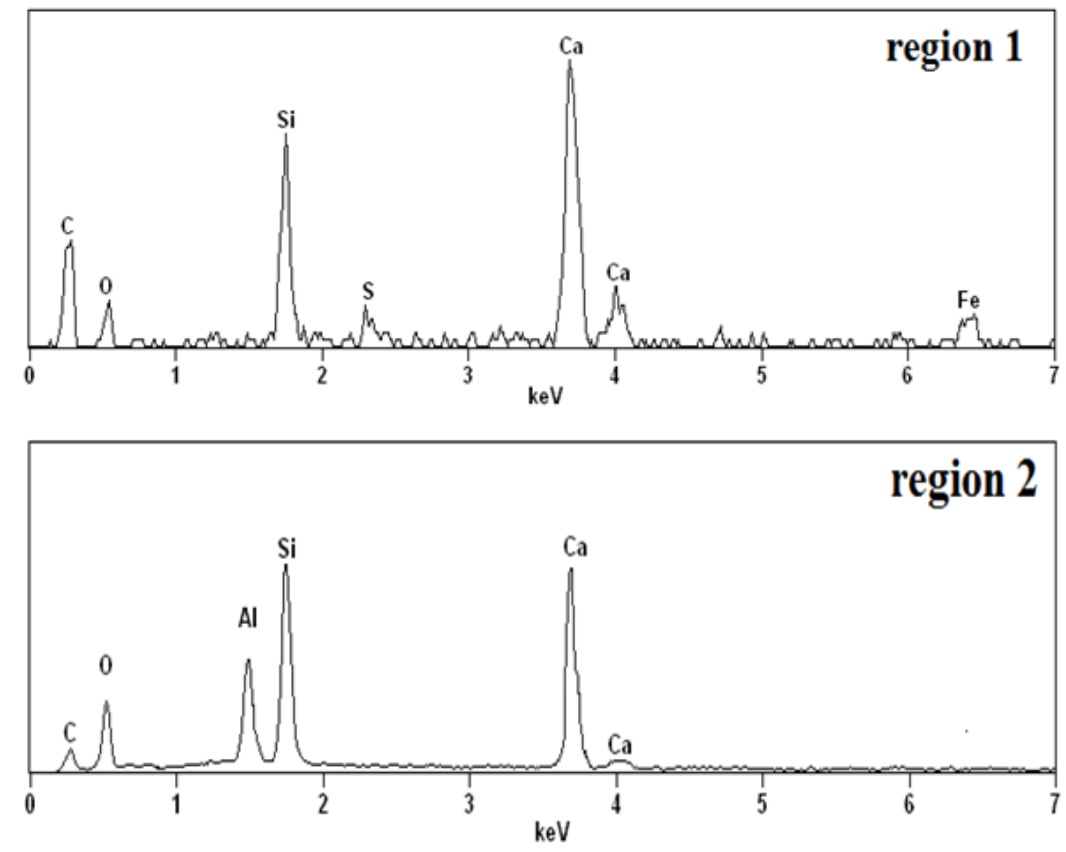

Figure 7. EDS spectrums of marked region 1 and 2 in Fig. 6

\subsubsection{Analysis for the morphological characteristics of hydration products}

Fig. 6 and Fig. 7 show the SEM images and energy dispersive spectroscopy (EDS) spectra of the internal section and external surface of the AAC pore wall. The hydration products inside the pore wall (Fig.6 (a)) were densely clustered, and the gel-like hydrated products and a large number of acicular or willow-shaped tobermorite were intertwined with each other to form a cohesive structure, and on the outer surface (Fig. 6 (b)) were relatively high-purity leaf-shaped tobermorite (clear grain boundary, and uniform size) which were intertwined together to form crystal continuum [14-17]. Combined with the XRD pattern, with the progress of autoclave curing process, the hydration products inside the product changed in stages, further leading to the changes in the microstructure [18] due to the limitation and synchronicity of tobermorite crystals. In addition, owing to the existence of the pore structure, the crystals had different compositions and growth spaces on the inside and outside surfaces of the pore walls, which also caused large differences in their microstructures. Fig. 7 shows the EDS data of calibration regions 1 and 2 marked in Fig.6 (a) and Fig.6 (b), respectively. The analysis concluded the calcium-rich CSH crystals, and the lamellar tobermorite crystals.

Under autoclaving conditions, $\mathrm{Ca}(\mathrm{OH})_{2}$ (formed from the hydration of calcium materials) in the mixed slurry hydrated with free $\mathrm{SiO}_{2}$ and $\mathrm{Al}_{2} \mathrm{O}_{3}$ in the GTS to obtain hydrated minerals such as tobermorite and $\mathrm{CSH}(\mathrm{B})$. In the early stage of autoclaving curing, the ettringite crystal phase formed in early cement hydration, and the excess gypsum in the system reacted with $\mathrm{Al}_{2} \mathrm{O}_{3}$ in the GTS under steam curing environment to produce the foliated single-alkali AFm crystals. At this time, the surface of the mixture particles was fully hydrated to form wellcrystalline and more hydrated products. With the number of crystals constantly increasing, the interval between crystals became smaller, and there were more contacts between them. Thus, the continuum was continuously formed between the crystals, and then formed a huge crystalline network structure, which is completely stronger than the condensed structure, with better performance.

\section{CONCLUSIONS}

(1) The GTS can be used as the main siliceous materials to prepare the qualified products of A3.5 and B06 AAC in accordance with national standards. The optimized ratio is determined: the specific surface area of the GTS is $362 \mathrm{~m}^{2} \cdot \mathrm{kg}^{-1}$, the mass ratio of GTS, lime, OPC, FGDG is $62: 24: 9: 5$, the water-to-material ratio is 0.61 , and the amount of aluminium powder and foam stabilizer added is $0.06 \%$ and $0.0256 \%$ of the total dry materials respectively.

(2) Under autoclave curing conditions, $\mathrm{Ca}(\mathrm{OH})_{2}$ formed by hydration of the calcium materials in the mixed material reacted with free $\mathrm{SiO}_{2}$ or free $\mathrm{Al}_{2} \mathrm{O}_{3}$ in GTS, quartz sand to generate the tobermorite. The crystal clusters of the hydration product were intertwined with the aggregates to form a good network dense structure, which has a positive effect on improving the strength of the product.

(3) At normal temperature and pressure, the GTS is an inert industrial waste residue, and after milling and activation it can show good activity under high temperature, high pressure and alkaline environment. The dissolved free $\mathrm{SiO}_{2}$ or free $\mathrm{Al}_{2} \mathrm{O}_{3}$ is active and participates in chemical reactions, which is conducive to improving the crystallinity of hydration products.

\section{ACKNOWLEDGMENTS}

The authors gratefully acknowledge financial support from China Postdoctoral Science Foundation (2016M602082), supported by Natural Science Foundation of Hebei Province (E2018402119), supported by Natural Science Foundation of Shaanxi Province (2019JLM-49), supported by Shaanxi Science and Technology Benefit People Project (2018ZY-HM-01), supported by Science and Technology Research Project of Higher Education Universities in Hebei Province (ZD2016014, QN2016115), supported by Comprehensive Utilization of Tailing Resources Key Laboratory of Shaanxi Province (2017SKYWK008), supported by Jiangxi Postdoctoral Daily Fund Project (2016RC30), supported by Jiangxi Postdoctoral Research Project (2017KY19), supported by State Key Laboratory of Solid Waste Reuse for Building Materials (SWR-2019-008). 


\section{REFERENCES}

[1] Li L, Xie C, Cheng D M, Feng Y M., J. Energy Environmental Protection, 26(3), 1 (2012).

[2] Huang J Z, Wang J W., Development report on comprehensive utilization of large industrial solid waste from 2010 to 2011, J. Beijing, China Light Industry Press, (2012).

[3] Kurama H, Topcu I B, Karakurt C., Journal of Materials Processing Technology, 209, 767 (2008).

[4] Walczak P, Szymański P, Różycka A., J. Procedia Engineering, 122, 39 (2015).

[5] Li D Z, Ni W, Zhang J W, Wu H, Zhang Y Y., Journal of the Chinese Ceramic Society, 39(4), 708 (2011).

[6] Bouvard D, Chaix J M, Dendievel R, Fazekas A, Létang J M, Peix G, Quenard D., J. Cement and Concrete Research, 37(12), 1666 (2007).

[7] Narayanan N, Ramamurthy K., J. Cement and Concrete Research, 30(3), 457 (2000).

[8] Narayanan N, Ramamurthy K., J. Cement and Concrete Composites, 22(5), 321 (2000).

[9] Lin G, Wang C L, Qiao C Y, Cui H L, Chen L, Yu S., J. Romanian Journal of Materials, 46(3), 334 (2016).

[10]Cui X W, Wang C L, Ni W, Di Y Q, Cui H L, Chen L., J. Romanian Journal of Materials, 47(1), 46 (2017).

[11]Liang X Y, Yuan D X, Li J, Wang C L, Lin X R, Chang N., J. Romanian Journal of Materials, 48(3), 381 (2018).

[12]Wang C L, Ni W, Zhang S Q, Wang S, Gai G S, Wang W K., J. Construction and Building Materials, 104, 109 (2016).

[13]Torsten S., J. Concrete Precasting Plant and Technology, 70(2), 136 (2004).

[14]Hauser A, Eggenberger U., J. Cement and Concrete Research, 29(3), 297 (1999).

[15]Huang X Y, Ni W, Cui W H, Wang Z J, Zhu L P., J. Construction and Building Materials, 27(1), 1 (2012).

[16]Bensted J, Barnes P. Structure and performance of cements, 2nd edition [M]. New York: Spon Press, 2002.

[17]Zhang N, Liu X M, Sun H H, Li L T., J. Journal of hazardous materials, 185(1), 329 (2011).

[18]Huelya K, Thomas C., J. Cement and Concrete Research, 33, 1423 (2003). 